\title{
Review Paper on the Study of Common and Plastic Aggregate (Recycled Aggregate)
}

\author{
Rohit Khobragade, Krunal Nikose, Sandhya Ilame, Sonam Kale, Akshay Chakole, Prof. Shital Navghare \\ Department of Civil Engineering,
} JDCOEM

\begin{abstract}
Recent technology has also improved the recycling process. In this fast-growing world, the volume of construction of waste has suddenly increased in the recent decades. In a rapid industrialized world recycling play a very vital role to save our natural resources which are very limited. And we see that the various countries like America, china and other countries are widely adapt the recycled aggregates in construction.

The healthy and sustainable reuse of plastic offers a least of advantage, the sustainability of common aggregate with respect to recycled plastic aggregate in construction and its advantage are discussed. The initial question arises here of its strength and heat of hydration so tests are conducted to determine physical properties of both aggregate \{common aggregate and plastic aggregate\} such as specific gravity also crushing value impact value etc. so we attempt to compare physical properties of plastic aggregates and common aggregates.

This study aimed to review on the common aggregate and the plastic aggregate and in this paper, we mostly focused on the plastic aggregate how we used plastic (recycled) aggregate in the larger construction. In this study, plastic coarse aggregates were used in place of natural coarse aggregates, some recent studies show that it can be used construction industry due to some of its properties like inert behaviour, resistance to degradation etc.
\end{abstract}

Keywords- About - Recycled Aggregate, Aggregate, Construction, Material.

\section{INTRODUCTION}

The demolition of old building and with respect to their traffic infrastructure and their exchange with new once is the frequent phenomenon in large part of world, as we all know that the rapid industrialization required the large amount of construction material also land requirements

In the present study the recycled plastics were used to prepares the coarse aggregates thereby providing the sustainable option to deal with the plastic waste which is todays headache. There are so many recycling plants all over India but plastics are recycled it lose its strength with the plastic waste.

The rising needs of middle-class and lower-class peoples and abilities of to satisfy them to cheaper prize as compared to other materials like the glass and metals has to contributes to an increased consumption of plastics in last five years.

Plastics have become a crucial part of our current lifestyle, and the worldwide plastic production has increased vastly during the past 50 years. Plastics have been used progressively in a large variety of products because of their favourable properties,

including low density, high strength-to-weight ratio, high durability, ease of design and production, and low cost.
Plastic is nearly inert that is it get very less affected by the chemicals and have higher durability.

So, from above consideration we confess that we must preforms various tests on the aggregate like common aggregate and plastic-coated aggregate and compared all the physical properties and all required test and explores such a new thing which will used in future of civil engineering.

BASES OF NATURAL AGGREGATE: -

There are two primary sources of natural aggregate:

(1) exposed or near-surface bedrock that can be crushed,

(2) deposits of sand and gravel.

Sources for these basic materials can be grouped into three main areas: Mining of mineral aggregate deposits, including sand, gravel, and stone; use of waste slag from the manufacture of iron and steel; and recycling of concrete, which is itself chiefly manufactured from mineral aggregates.

\section{BASES OF RECYCLED AGGREGATE: -}

Construction and demolished waste generated due to natural disasters, for future development the old buildings are replaced by new ones, and war inflicted damages. Crushing of Portland concrete pavement. Tested specimens from laboratory Concrete from ready mix concrete plants and precasting units worn out rail ballast.

\section{IDENTIFY, RESEARCH AND COLLECT IDEA}

Plastic needs no introduction as it is the widely used material now a days on our Earth. Due to its properties like strength, durability and easy processing it can be used for many purposes.

Studies shows that plastic is nearly inert that is it get very less affected by the chemicals and have higher durability. Disposal of plastic waste is a huge problem as due to absence of organic compounds, it is non-decomposable material and proves to be a threat to our environment as it has many health hazards.

As decomposition of plastic is a serious problem as it takes very long time and adversely affection the environment in many ways. So, we can use it in construction, where we need life of structure to be improved and use of waste plastic after small processing can help us to reduce the waste in the environment which is new motto of civil engineering.

\section{STUDIES AND FINDINGS}

$>$ we study the properties of aggregates.

$>$ We doing the comparative study while on common aggregates and plastics aggregate.

$>$ we analyze which one is good in construction. 


\section{$>$ Identification of properties of aggregate:}

Although some variation in aggregate properties is expected, characteristics that are considered include:

- grading.

- durability.

- $\quad$ particle shape and surface texture.

- abrasion and skid resistance.

- unit weights and voids.

- $\quad$ absorption and surface moisture.

\section{$>$ Identification role of aggregate in practical life: -}

Aggregate in concrete is a structural filler, but its role is more important than what that simple statement implies. The composition, shape, and size of the aggregate all have significant impact on the workability, durability, strength, weight, and shrinkage of the concrete.

$>$ Utilization of aggregate all over world: -

Construction aggregate, or simply "aggregate", is a broad category of coarse to medium grained particulate material used in construction, including sand, gravel, crushed stone, slag, recycled concrete and geosynthetic aggregates. Aggregates are the most mined materials in the world. Aggregates are a component of composite materials such as concrete and asphalt concrete; the aggregate serves as reinforcement to add strength to the overall composite material. Due to the relatively high hydraulic conductivity value as compared to most soils, aggregates are widely used in drainage applications such as foundation and French drains, septic drain fields, retaining wall drains, and roadside edge drains. Aggregates are also used as base material under foundations, roads, and railroads. In other words, aggregates are used as a stable foundation or road/rail base with predictable, uniform properties (e.g. to help prevent differential settling under the road or building), or as a lowcost extender that binds with more expensive cement or asphalt to form concrete.

\section{LITERATURE REVIEW SURVEY: -}

Punitha $P$ on 07 March 2019[1], From the experimental results, it can be concluded that, The workability (slump test) of RAC is same for NAC because the rate absorption of RA is equal to NA. The general properties of RA and NA are same in the specific gravity, water absorption, and Aggregate impact value. The sieve Analysis test of coarse Aggregate and Fine Aggregate are compared with RAC.

Prabhat kumar et al[2] (2016)presented a review of existing literature work for understanding thoroughly about RCA and the concluded from various studies that Natural aggregate can be used with recycle aggregate with a ratio of 80:20 and 70:30. Higher ratio of Recycle aggregate can worsen the properties and strength of mix and due to use of recycled aggregate in construction industry it can slow the impact of waste on environment. Also it will promote sustainable growth

Praveen Mathew et. al.[3] in 2013 study the use of Recycled Plastics as Coarse Aggregate for Structural Concrete. They performed test on concrete with various proportions of plastic aggregates in replacement of coarse aggregates and found the optimum result at $22 \%$ replacement of coarse aggregates with plastic aggregates. They further performed the test for other properties on concrete with $22 \%$ plastic aggregates and found that concrete with plastic aggregates was weaker in fire resistance

LhakpaWangmoThinghTamanget. al.[4] in 2017 performed experiment on Plastics in Concrete as Coarse Aggregate. They performed the testing of mechanical properties of concrete containing Plastic aggregates They use plastic aggregates in proportion of $10 \%, 15 \%$, and $20 \%$. They found marginal reduction in strength and suggested the optimum result as $15 \%$ replacement

Elango A and Ashok Kumar A[5] in 2018 performed study concrete with plastic fine aggregates. They used OPC 53 grade, River sand and crushed aggregates. They used plastic in place of fine aggregates in proportion of $10 \%, 20 \%$ and $30 \%$. They test mechanical and durability properties on their concrete samples. They found the decrease in strength of concrete. But found that the concrete shows good results against acid attacks and increase in elasticity. So they concluded that the plastic aggregate concrete can be used in place where we need less compressive strength but more durability.

Shi-cong Kou , Chi-sun Poon a, Francisco Agrela [6]in 2011 prformed study on The compressive strength of concrete containing recycled aggregate at 1, 4, 7, 28 and 90 days was lower than that of the control specimen, but could be compensated by the use of $10 \% \mathrm{SF}$ or $15 \% \mathrm{MK}$. However, the use of $30 \%$ FA or $55 \%$ GGBS lowered the strength.

Chaitradip Sarkar , Parikshit Chauhan ,NavedKhan ,Abu Sufiyan Khan ,Mohammad Aquib [7]Comparative Study of Natural and Recycled Aggregate Concrete in this paper they studied According to the test results, the performance of recycled aggregate concrete, even with the total replacement of coarse natural with coarse recycled aggregate, is satisfactory and shows that there is enormous scope of this aggregate in at present and in future, not only in terms of the mechanical properties,

Use of Recycled Aggregates in concrete , S.K. SINGH, Scientist, Structural Engineering Divis, Central Building Research Institute, Roorki And P.C. Sharma,Head(Retd.),Material Sciences, SERC and editor New Building Materials and Construction World, New Delhi, Chairman, Indian Concrete Institute U.P. Gaziabad Centre[8] in this paper they studied about Recycling and reuse of building wastes have been found to be an appropriate solution to the problems of dumping hundred of thousands tons of debris accompanied with shortage of natural aggregates. The use of recycled aggregates in concrete prove to be a valuable building materials in technical, environment and economical respect. Recycled aggregate posses relatively lower bulk density, crushing and impact values and higher water absorption as compared to natural aggregate. The compressive strength of 
recycled aggregate concrete is relatively lower up to $15 \%$ than natural aggregate concrete. The variation also depends on the original concrete from which the aggregates have been obtained. The durability parameters studied at $\operatorname{SERC}(\mathrm{G})$ confirms suitability of RCA \& RAC in making durable concrete structures of selected types.

Parekh D. N. et al (2011)[9] studied the basic properties of recycled fine aggregate and recycled coarse aggregate. He also compares these properties with natural aggregates and resulted that recycled aggregate.

Y P Gupta[10] -USE Of Recycled Aggregate In Concrete Construction:A Need For Sustainable Environment studied the The work presented in this paper evaluates the effect of recycled aggregate quality on the properties of concrete. Evaluation of the aggregate physical and mechanical properties showed an acceptable variation in properties when samples were collected and evaluated from unknown source over 6 months. However, limitations in gradation requirements; high absorption and aggregate strength could be resolved during the proportioning stage and by achieving high packing density.

\section{IMPROVEMENT AS PER REVIEWER}

In this review paper we studied that the rising needs of middle class and lower-class people and ability of satisfy them to cheaper price as compared to other materials, in this we use the primary source of aggregate. Studies shows that the plastic is nearly inert that it gets very less affected by the chemicals and have higher durability. As plastic is very dangerous for decomposition as it takes very long and adversely effects on environment. from this we are improving the properties for reuse.

As the previous study of the authors they can mainly focused on the waste plastics and its utilization in construction so there is a need of the improvement in our paper we are make an review paper so we study on both common aggregate and the plastic aggregate.

While studying on plastic and the common aggregate we can analyze that we can use it as a partial replacement of an coarse aggregate also we can be used in the bituminous roads section as well as we want higher flexibility.

\section{CONCLUSION}

As we can studied the research of all authors from that we can conclude that there is some research required in plastic aggregate to used it in partial replacement of the common aggregate.

As we can see nowadays the depletion of natural resources in main parts so we have to move towards our next option i.e. plastic or recycled aggregate so from our study on plastic aggregate it can be implies that we can gives an better option to society as well to our world.

From the above study the following conclusions can be drawn.

* Due to use of recycled aggregate in construction industry it can slow the impact of waste on environment.
* Higher ratio of Recycle aggregate can worsen the properties and strength of mix.

* It is clear that recycled aggregate can be used with natural aggregates.

* It can be studied that again much more enhancement is needed in the recycled aggregate to replace common aggregate.

\section{REFERENCES}

[1] Punita p "Study of Natural Aggregate and Recycled Aggregate" International Journal for Research \& Development In Technology, Volume-9,Issue-3(Mar-18) ISSN (O) :- 2349-3585.

[2] Prabhat kumar, Abhishek Kumar, Mohd. Afaque Khan, "A review paper on experimental study for recycle concrete", Volume 3, Issue 3, pp. 1617-1619, 2016 [9] Anurag Gautam, Kirti Chandraul,

[3] Praveen Mathew, ShibiVarghase, Thomas Paul ,EldhoVarghase, “ Recycled Plastic as coarse aggregates for structural concrete", International Journal for Innovative Research in Science, Engineering and Technology, Volume 2, Issue 3, 2013, ISSN 2319-8753

[4] LhakpaWangmoThinghTamang, TsheringWangmo, Karma TsheringDarjay, Karma SangayPhuntsho, PhuntshoNamgyal, UgyenWangchuk "Use of Plastics in Concrete as Coarse Aggregate" International Journal of Education and Applied Research, Volume 7, Issue 5, 2017, ISSN (Print) 2249-4944, ISSN(Online) 2348-0033.

[5] Elango A and Ashok Kumar A "Study on Partial Replacement of plastic waste as fine aggregate in concrete" International Journal of Current Engineering And Scientific Research, Volume 5, Issue 5, 2018, ISSN (Print):2393-8374, ISSN (Online): 2394-0697

[6] Shi-cong Kou , Chi-sun Poon a, $\Uparrow$, Francisco Agrela Comparisons of natural and recycled aggregate concretes prepared with the addition of different mineral admixtures.

[7] Chaitradip Sarkar, Parikshit Chauhan ,NavedKhan,Abu Sufiyan Khan ,Mohammad Aquib Comparative Study of Natural and Recycled Aggregate Concrete

[8] Use of Recycled Aggregates in concrete, S.K. SINGH, Scientist, Structural Engineering Divis, Central Building Research Institute ,Roorki And P.C. Sharma,Head(Retd.),Material Sciences, SERC and editor New Building Materials and Construction World, New Delhi, Chairman, Indian Concrete Institute U.P. Gaziabad Centre

[9] Parekh D. N. and Dr. Modhera C. D., "Assessment of recycled aggregate concrete", Volume 2, Issue 1, pp. 1-9,March 2011

[10] Y P Gupta -USE Of Recycled Aggregate In Concrete Construction:A Need For Sustainable Environmentll 34th Conference on OUR WORLD IN CONCRETE \& STRUCTURES 16 - 18 August 2009, Singapore. 